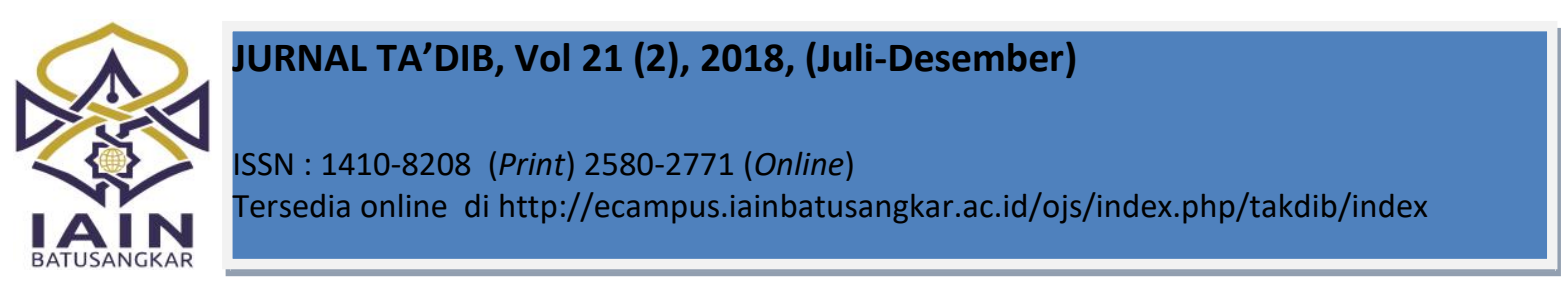

\title{
PEMBELAJARAN ENGLISH PUBLIC SPEAKING BERBASIS PROJECT-BASED LEARNING
}

\author{
Difiani Apriyanti \\ Politeknik Negeri Padang \\ E-mail: difi.apriyanti@gmail.com

\section{Sumira} \\ Politeknik Negeri Padang \\ E-mail: sumiradoano@gmail.com

\section{Sariani} \\ Politeknik Negeri Padang \\ E-mail: sarianipasni@yahoo.com
}

\begin{abstract}
Abstrak: Learning Public Speaking does not only include good speaking English but also gives attractive performance. However, this is not easy due to the fearness and anxiety with various symptoms such as a rapid heartbeat, wet palms, or vibrating sounds. In order to minimize the obstacles, Project Based Learning $(P B L)$ is designed. The students are assigned to be public speakesr sharing the information about agency programs to public. The project was eventually documented in the form of videos. To find out the success of the learning, a qualitative descriptive study was conducted on the video project. The subject of the research was a female student whose public speaking videos were analyzed. The sample was selected purposively because women have greater public speaking anxiety than men do. As the result, at first, the students did not have problems in making the text (content) to be presented, but it was problematic in the delivery. The first video shows public speaking fear that has not been resolved so that delivery occurs at a low level. Secondly, while in the second video it shows self confidence resulting a high delivery capability. It can be concluded that having one real experience as a public speaker makes the student able to overcome public speaking fear or anxiety.
\end{abstract}

Kata Kunci: Public Speaking, PBL, Video

\section{PENDAHULUAN}

$\mathrm{P}$ oliteknik Negeri Padang (PNP) merupakan salah satu perguruan tinggi vokasi di Indonesia dengan $40 \%$ pengajaran berfokus pada teori, dan $60 \%$ pada praktek yang ditunjang dengan berbagai sarana pendukung seperti labor dan bengkel lengkap dengan peralatannya. Pendidikan vokasi diyakini mampu menghasilkan output yang siap kerja ini, dengan mempertimbangkan pengajaran yang diberikan kepada mahasiswanya sesuai dengan kebutuhan industri terkini, antara lain dengan melaksanakan berbagai kunjungan industri, pengadaan workshop dan seminar industri, dan menjalin kerjasama $(\mathrm{MoU})$ dengan industri. Disamping ketersediaan fasilitas, kreativitas para pengajarpun sangat dibutuhkan terutama dalam memberikan gambaran yang jelas tentang hal yang akan dihadapi mahasiswa di dunia kerja nantinya, dan juga bagaimana cara menghadapinya. Sehingga, dengan memiliki foreknowldge ini, akan meningkatkan rasa percaya diri mereka dalam menghadapi kompetisi di dunia kerja. Hal ini juga berlaku pada mahasiswa Jurusan Bahasa Inggris, sebagai salah satu dari tujuh jurusan yang ada di PNP. Jurusan ini memfokuskan pengajarannya dalam bidang penterjemahan, penyiaran, dan public speaking. Untuk pengajaran English Public Speaking, selain melakukan praktek pengajaran di studio TV, yang sudah dilengkapi dengan peralatan 
seperti studio yang ada di stasiun TV, mahasiswa juga dijadwalkan untuk melakukan sebuah project. Untuk kegiatan ini, mahasiswa diharapkan untuk mampu tampil di luar lingkungan PNP, dan berhadapan dengan orang-orang yang belum mereka kenal sebelumnya.

Tentu saja, situasi yang tidak familiar bagi mereka ini, akan menimbulkan rasa kecemasan atau dikenal dengan public speaking fear. Gejala atau symptoms yang akan muncul pada setiap mahasiswa berbeda-beda seperti telapak tangan yang basah, tangan yang bergetar, detak jantung yang kencang, dan berbagai lainnya. Padahal, pada waktu yang bersamaan, mahasiswa tersebut diharapkan untuk mampu mengendalikan dirinya agar dapat memberikan performance yang terbaik. Hal ini sesuai dengan pernyataan Furmark (2002), yang mengatakan bahwa public speaking adalah ketakutan sosial yang paling umum terjadi pada individu dengan fobia sosial dalam masyarakat luas. Tantangan dalam memberikan first impression atau penampilan yang terbaik, tidak akan dilalui jika lokasi dan situasi yang diambil adalah kelas keseharian tempat belajar, dan di depan teman-teman sekelas yang sudah sangat dikenal.

Dalam kegiatan public speaking yang berbasis project ini, mahasiswa diminta untuk mengenali jasa, produk, atau program yang dimiliki oleh suatu tempat kerja, baik itu instansi, institusi, perkantoran, ataupun perusahaan. Mereka kemudian menelaah services yang mengalami kendala dalam perluasan informasinya, memilih salah satu, dan mengangkatnya sebagai project. Langkah berikutnya adalah pencarian data yang terkait. Mereka akan bertemu dengan orang-orang baru dan berada di tempat yang baru. Mereka harus pandai menggali informasi sebanyak-banyaknya dari setiap informan ini. Informasi yang didapat kemudian dirangkum menjadi sebuah nashkah yang menarik. Karena naskah dalam Bahasa Indonesia, proses terjemahan kedalam Bahasa Inggris harus dilakukan. Untuk membantu proses public speaking performance, mahasiswa menuangkan naskah tersebut kedalam que cards, dan menggunakannya selama proses tersebut. Kegiatan public speaking setiap mahasiswa direkam dalam bentuk videoe sebagimana yang disampaikan oleh Prince dan Felder (2016) bahwa produk akhir dari tugas yang berbasis project adalah laporan resmi dalam bentuk tulisan atau lisan.

\section{METODE PENELITIAN}

Penelitian ini merupakan penelitian deskriptif kualitatif. Data dikumpulkan dari public speaking performance yang didokumentasikan dalam video. Karena penelitian ini adalah penelitian deskriptif, maka data dianalisa secara deskriptif dengan menggunakan indikator kriteria professional public speaker.

Sampel dalam penelitian ini adalah seorang mahasiswi, dan untuk menjaga etika penelitian, siswi ini diberi inisial SFW. Sampel yang diambil adalah seorang perempuan karena menurut Shi and McCree (2015) Public Seaking Anxiety (PSA) atau kecemasan public speaking memang tergantung pada jenis kelamin, dan umumnya perempuan yang memiliki PSA yang tinggi. Pendapat ini juga didukung oleh Ferreira Marinho, et.al (2017) yang mengatakan bahwa sebagian besar mahasiswa yang melaporkan takut berbicara di depan umum adalah dari kalangan perempuan. 
Dalam menganalisa kemampuan public speaking maka dibagi menjadi dua yaitu konten dan penyampaian (delivery) Dalam mengemas konten, maka dinilai apakah mahasiswa mampu menyampaikan tujuannya, apakah kontennya disusun secara sistematik, apakah terdapat ide-ide pendukung, apakah contoh-contoh yang diberikan adalah yang menarik bagi penontonnya, dan apakah mahasiswa tersebut dapat menyimpulkan idenya secara baik. Sedangkan dalam penyampaiannya yang akan dilihat adalah cara berbicara mahasiswi tersebut dari sisi kejelasan dan ketepatan penggunaan kosakata, ketepatan nada suara, kecepatan suara, dan juga volume. Kenyamanan atau kepercayaan diri saat performance juga menjadi suatu penilaian.

Data juga diambil dari wawancara dengan SFW dengan menggunakan open question untuk mengetahui pandangan siswi tersebut terhadap model pembelajaran Project Based Learning tersebut. Kesulitan atau hambatan yang dilalui oleh mahasiswi tersebut nantinya akan dijadikan sebagai bahan evaluasi. Dalam penelitian ini instrument yang digunakan adalah berupa checklist dan question lists.

\section{HASIL DAN PEMBAHASAN:}

Video yang dibuat adalah penyebarluasan informasi program Bank Sampah yang dimiliki oleh Dinas Kebersihan dan Pertamanan Kota Padang bersama dengan Pemerintah Kota Padang. Alasan pemilihan program ini adalah terbatasnya atau minimnya pengetahuan dan keterlibatan masyarakat kota Padang terhadap program ini dan juga kondisi Tempat Pembuangan Akhir (TPA) kota Padang yang berada dalam kondisi kritis atau memprihatinkan.
Video yang berdurasi lebih kurang 11 menit, proses shootingnya mengambil beberapa angle seperti sungai yang penuh dengan sampah, bak-bak sampah pemberian pemerintah kota Padang, Bank Sampah di Padang, dan TPA kota Padang. Sangat diharapkan dengan adanya video ini dapat menggerakkan keinginan penduduk kota Padang untuk ikut aktif dalam meyelamatkan TPA kota Padang dengan cara berperan aktif sebagai customer Bank Sampah.

Dalam video ini, Performance SFW dianalisa dari sisi konten dan penyampaian. Dalam penampilan sebagai seorang public speaker, SFW mengungkapkan tujuan presentasinya dengan jelas. Disini SFW menjelaskan tujuan dari penampilannya adalah memberikan informasi tentang program Bank Sampah yang di keluarkan oleh Dinas Kebersihan Kota Padang bersama dengan pemerintah Kota Padang. Konten yang disampaikan tersusun dengan baik.

Di dalam konten juga terdapat kata viewers yang berguna menghubungkan konten dengan penontonnya. SFW mampu menyusun konten dengan membawa penonton kearah pemahaman tentang program Bank Sampah, dan keuntungan sebagai pelanggan bank tersebut. Setelah memaparkan keuntungan yang didapatkan sebagai pelanggan, SFW membawa penonton ke arah 'sentuhan perasaan' jika program ini tidak berjalan, maka kota Padang tidak akan memiliki tempat akhir pembuangan sampah. Penyusunan konten ini dapat meningkatkan ketertarikan penonton terhadap program yang ditampilkan. Konten juga diatur secara logis, yaitu diawali dengan pemahaman terhadap Bank Sampah, tujuan dari program yang dibuat untuk masyarakat, kondisi terkini TPA, akibat yang akan terjadi kedepannya jika Bank Sampah tidak 
dijalankan, serta dampak positif yang akan muncul jika ada perhatian masyarakat kota Padang terhadap program Bank Sampah ini.

Dalam presentasinya, SFW juga memberikan penjelasan dengan memberikan contoh-contoh yang dilengkapi dengan gambar yang mendukung, seperti ketika dikatakan pemerintah telah menyediakan bak-bak sampah untuk masyarakat, maka akan diperjelas dengan gambar-gambar bak sampah yang berada di jalan-jalan kota Padang. Dalam performance nya, SFW juga mampu membentuk kesimpulan yang sangat baik yaitu dengan cara mengajak penonton untuk ikut terlibat sebagai nasabah Bank Sampah dengan mengambil istilah-istilah terkait mengenai Bank Sampah, yaitu 3R Reduce, Reuse, dan Recycle untuk diingat

Video public speaking ini telah melalui proses penyuntingan dua kali sehingga menghasilkan dua video utuh. Hal ini disebabkan SWF mengalami public speaking fear pada performance nya. Kecemasan yang dialami SFW berakibat pada ketidak jelasan pengucapan. Hal ini dikarenakan salah penempatan stressing kosakata sehingga maksud yang ingin disampaikan tidak dimengerti. Tekanan suara yang dihasilkan juga datar sehingga pokok-pokok penting yang ingin disampaikan kepada penonton tidak tercipta. Selain bermasalah dengan tuturan, kecemasan SFW juga terlihat pada ekspresi wajah. Ketegangan pada wajah terlihat dengan bola mata yang melotot dan senyuman yang tidak pernah hadir dalam penampilannya. Selain itu, gerakan atau body movement yang dilakukan SFW tidak natural, seperti saat memperkenalkan material sampah yang dapat dikirim ke Bank Sampah, SFW memegang contoh material sampah dari satu material ke material berikutnya dengan keterburuan. Dengan performance yang kurang memuaskan, SFW diminta untuk melakukan projectnya kembali. Hancock, et.al (2010) menyatakan bahwa perancangan dan penyampaian pidato dengan menyesuaikan suara dan mekanisme pidato akan berhasil mengurangi kecemasan public speaking dan meningkatkan perasaan percaya diri dan kompetensi mahasiswa tersebut. Lee dan Liang (2012) juga berpendapat bahwa kesulitan yang dihadapi dalam berpidato berhubungan dengan konseptual pidato yang dikuasainya.

Pada video Public Speaking yang kedua ini, performance SFW dalam penyampaian konten terlihat lebih nyaman. Kosakata yang disampaikan lebih merupakan kata-kata yang lazim digunakan sehingga sangat besar kemungkinan dapat dimengerti oleh penonton dari latar belakang pendidikan yang berbeda. Karena kejelasan kata yang digunakan, maka keraguan terhindari. Pada video kedua ini, SFW lebih jelas penekanan suaranya. Untuk hal yang harus mendapatkan penekanan, SFW menaikkan volume suaranya. Contohnya adalah saat mengutarakan 3R, SFW memberikan tekanan suara yang penuh dan speed yang pelan pada setiap kata, agar dapat dipahami dan diingat oleh penonton. Dan hal ini diakui oleh SFW saat diwawancara bahwa ia merasa lebih nyaman dan rileks saat melakukan public speaking performance yang kedua. Situasi ini dikarenakan ia sudah memiliki pengalaman public speaking di tempat yang baru dan didepan orang-orang yang baru dikenalnya. Hal ini sesuai dengan teori experential learning oleh McLeod (2017) yang mengatakan bahwa experential learning ini dimulai dengan memiliki pengalaman kemudian mereview atau bercermin pada pengalaman, dan kemudian menyimpulkan apa yang dialami dari 
pengalaman dan berakhir dengan mencoba kembali apa yang telah dipelajari dari pengalaman. Hal ini didukung oleh Goberman (2011) yang menunjukkan bahwa praktik memberikan dampak pada kefasihan pada public speaking performance dibandingkan public speaker yang baru memulai.

\section{KESIMPULAN DAN REKOMENDASI}

Dari penelitian yang dilakukan ini, dapat dilihat bahwa memang benar rasa kecemasan atau ketakutan akan muncul jika belum ada pengalaman nyata menjadi seorang public speaker yang memberikan performance di tempat yang baru dan di depan orang yang baru dikenal. Penelitian ini juga meunjukkan bahwa hanya dengan satu pengalaman nyata, dapat menimbulkan rasa percaya diri seorang public speaker dan hal ini dapat dilihat dari cara penyampaian (delivery) pertunjukkannya. Tetapi pengalaman nyata tidak mempengaruhi kemampuan seorang public speaker membangun konten naskah yang akan disampaikan dalam performance nya.

Disisi lain, pengucapan merupakan salah satu bagian penting yang harus diasah pada mahasiswa public speaking. Penekanan pada suara akan memberi pengaruh yang besar pada kepercayaan dirinya pada saat performance.

Oleh karena itu sangat direkomendasikan bahwa dalam pengajaran Public Speaking diharapkan tugas yang diberikan kepada mahasiswa adalah tugas yang membawa mereka ke kerja praktek lapangan tanpa lupa memberi tau terlebih dahulu konsep-konsep delivery yang baik.

\section{REFERENSI}

Ferreira Marinho, A. C., Mesquita de Medeiros, A., Côrtes Gama, A. C., \& Caldas Teixeira, L. (2017). Fear of Public Speaking: Perception of College Students and Correlates. Journal of Voice, 31(1), 127.e7127.e11. doi:10.1016/j.jvoice.2015.12.012e.

Furmark, T. (2002). Social phobia: overview of community surveys. Acta Psychiatrica

Goberman, A. M., Hughes, S., \& Haydock, T. (2011). Acoustic characteristics of public speaking: Anxiety and practice effects. Speech Communication, 53(6), 867-876. doi:10.1016/j.specom.2011.02.005

Hancock, A. B., Stone, M. D., Brundage, S. B., \& Zeigler, M. T. (2010). Public Speaking Attitudes: Does Curriculum Make a Difference?

Journal of Voice, 24(3), 302-307. doi:10.1016/j.jvoice.2008.09.007.

Lee, Yow-jyy Joyce and Liang, Jung-Chin. 2012 Using Video Technology to Diagnose EFL Students' Cognitive Learning Difficulties in Public Speaking.

McLeod, S. A. (2017). Kolb - learning styles. Retrieved from https://www.simplypsychology.org/ learning-kolb.html.

Prince, M. And Felder, R.M. (2016). Inductive Teaching and Learning Methods: Definitions, Comparisons, and Research Bases. Journal of Engineering Education, Vol. 95, No. 2, pp.123-138. 
Shi, X., Brinthaupt, T. M., \& McCree, M. (2015). The relationship of self-talk frequency to communication apprehension and public speaking anxiety. Personality and Individual

Differences, 75 , 125-129. doi:10.1016/j.paid.2014.11.023.

\section{Article Metadata:}

Apriyanti, D. Sumira. Sariani. (2018). English Public Speaking Instruction Based on Project-Based learning. Ta'dib, 21 (2), 69-74.

http://dx.doi.org/10.31958/jt.v21i2.1235

Keywords: Public Speaking, PBL, Video

Coresponding author: Difiani Apriyanti, Politeknik Negeri Padang, difi.apriyanti@gmail.com 